\title{
Effect of postpartum depression on women's mental and physical health four years after childbirth
}

Fatemeh Abdollahi ${ }^{1}$ and Mehran Zarghami ${ }^{2}$

${ }^{1}$ Department of Public Health, Faculty of Health and Health Sciences Research Centers, Addiction Institute; Mazandaran University of Medical Sciences, Sari, Islamic Republic of Iran. ${ }^{2}$ Department of Psychiatry, Faculty of Medicine; and Psychiatry and Behavioral Sciences Research Center, Addiction Institute; Mazandaran University of Medical Sciences, Sari, Islamic Republic of Iran. (Correspondence to: Mehran Zarghami: mzarghami@mazums. ac.ir or mehran.zarghami@gmail.com)

\begin{abstract}
Background: Postpartum depression has been shown to affect women's health in the long term but no studies have assessed this in the Islamic Republic of Iran.

Aims: This study determined the prevalence of current depression and illness in women who had experienced postpartum depression four years after childbirth, and evaluated the factors associated with current depression.

Methods: In a cohort study in 2009, 1801 pregnant women without depression at 32-42 weeks of pregnancy attending Mazandaran primary healthcare centres were examined for postpartum depression using the Edinburgh Postnatal Depression Scale (EPDS). After four years, 204 women of the original cohort with postpartum depression and 467 without postpartum depression were again evaluated using the EPDS, and other questionnaires to determine the prevalence of current depression and other health problems. Multivariable logistic regression analysis was used to evaluate the factors associated with current depression and other health problems.

Results: The mean age of the women was 30.13 (SD 5.21) years. Women with postpartum depression were two times more likely to experience depression four years after childbirth ( $\mathrm{OR}=2.16,95 \% \mathrm{CI}: 1.38-3.36)$. They were also significantly more likely to experience chronic diseases ( $\mathrm{OR}=2.49,95 \% \mathrm{CI}: 1.38-4.50$ ) and score higher on the General Health Questionnaire (OR $=2.50,95 \%$ CI: $1.38-4.50)$.

Conclusions: Postpartum depression predisposes women to later depression and other mental and physical health problems. Women with postpartum depression need to be identified and provided with support and appropriate interventions to avoid later health problems.
\end{abstract}

Keywords: Mental health, depression, postpartum, pregnancy, Iran

Citation: Abdollahi F; Zarghami M. Effect of postpartum depression on women's mental and physical health four years after childbirth. East Mediterr Health J. 2018;24(10):1002-1009. https://doi.org/10.26719/2018.24.10.1002

Received: 20/02/16; accepted: 12/07/17

Copyright (c) World Health Organization (WHO) 2018. Some rights reserved. This work is available under the CC BY-NC-SA 3.0 IGO license (https:// creativecommons.org/licenses/by-nc-sa/3.o/igo)

\section{Introduction}

Depression is a significant public health concern with a worldwide prevalence of $4.7 \%(1,2)$. A study published in 2010 among the Iranian population reported a prevalence of depression of $4.1 \%$ (95\% CI: 3.1-5.1) with women being 1.95 times more likely to be depressed than men (3).

Postpartum depression, with a reported prevalence of $19.8-82.1 \%$ in some developing countries $(4,5)$, can affect a mother's relationship with her child $(4,6)$. In the Islamic Republic of Iran, the prevalence of postpartum depression has been reported to be $25.3 \%$ (95\% CI: $22.7-$ $27.9 \%)(6)$. Longitudinal studies have shown that this condition can have long-term effects on a child's growth and development and attachment to his/her mother $(7,8)$. It also affects women's mental health in the long term $(9,10)$. Because of postpartum depression episodes, these women may not be willing to get pregnant again (11). Suicide from psychiatric illness is the main cause of maternal death in the first postpartum year and may be a consequence of untreated postpartum depression $(12,13)$.
Maternal expectations and outlook were found to be a risk factor for the occurrence of subsequent problems for both mother and child $(10,14)$, and women with a history of postpartum depression have developed more depressive symptoms later $(14,15)$. The prevalence of depression has been examined in follow-up studies of women with postpartum depression $(14,16)$. The prevalence of recurrent depressive symptoms has been estimated to be range between $23 \%$ and $49 \%$ in different samples with different risk factors reported $(17,18)$. However, social differences between the samples could have affected these results. Few studies have followed up depressive symptoms in the long term in different populations (10) and no such studies have been done in Iranian women.

From January to June 2009, we conducted a longitudinal study among women during pregnancy and after delivery in Mazandaran Province (19). A high rate of postpartum depression (14.1\%) was identified (19). The current study aimed to follow up those women to investigate the prevalence of subsequent depression and other physical and mental illnesses 4 years later. 


\section{Methods}

\section{Study design and setting}

This was a longitudinal study conducted in Mazandaran primary health care centres (PHCCs) in northern Islamic Republic of Iran. These PHCCs are public centres providing preventive care and health education services for women, and are data surveillance centres for pregnancy and birth.

\section{Study sample}

In the original study (January to June 2009), a sample of women was followed from between 32 and 42 weeks of pregnancy to 12 weeks postpartum to determine the incidence and predictors of postpartum depression (19). In total, 2279 women participated in the original study, of whom 1801 had no symptoms of depression at 32-42 weeks of pregnancy, as assessed by the Edinburgh postnatal depression scale (EPDS). Women on pharmacological treatment for psychiatric disorders were excluded from the original study. Of the 1801 women, 1546 were followed until 12 weeks postpartum. For the present study, four years later, the PHCC records of the 1546 women were reviewed to identify eligible participants. Three groups of women were excluded from the present study: those who reported experiencing chronic diseases during the original study (women using daily medication), those with potential depression based on EPDS who were referred to a physician for treatment, and those who became pregnant during the four years. From 1546 women, all depressed women scoring above the EPDS threshold $(>12)$ during 12 postpartum weeks $(n=254)$ who met the eligibility criteria for this study were considered for inclusion after four years. Of the 254 women, 216 eligible women who attended the PHCCs for infant care and completed the consent form were recruited as the case group. The women were followed again from February to October 2013. In addition, 475 eligible women of the 1292 women without postpartum depression were randomly chosen as a control group. First, the sample size was determined for each city and PHCC. Then, a list was made of all eligible women without postpartum depression in each PHCC and each was assigned a unique number. Then, the required sample in each PHCC was selected by drawing numbers randomly. These women were asked to participant in the study when they were attending the PHCC (Figure 1).

Because of some difficulties in reaching and recruiting women in urban areas-some had changed address and some declined to participate-most women taking part in this study came from rural areas (59.9\%).

\section{Data collection}

Data were collected using four questionnaires:

- Iranian EPDS version (20)

- $\quad$ Life event rating scale (LERS) (21)

- 28-item general health questionnaire (GHQ-28) (22)
- A questionnaire asking about: chronic diseases (e.g. diabetes mellitus, hypertension, heart disease, and use of daily medication); acute diseases (e.g. infectious diseases, pain); other mental health problems (e.g. depression, anxiety), use of daily medication for chronic diseases in the past four years; PHCC location (rural, urban).

- A checklist including maternal/child characteristics (education, parity, child's age and sex).

The researchers and trained health care practitioners distributed the questionnaires to the eligible women. All the women were literate and completed the questionnaire in Farsi at the PHCC. All standardized questionnaires were already validated for the Iranian population (23-25). Data on the socioeconomic background, pregnancy course, medical history, birth weight and infant characteristics at the time of delivery were recorded in the original study (19).

According to the GHQ scores, participants were divided into 2 groups: unhealthy (score $>21$ ) and healthy (score $\leq 21$ ).

\section{Statistical analysis}

Data were analysed using SPSS, version 20. Continuous variables are presented as mean and standard deviation (SD), and categorical variables as number and percentage. The differences between the groups with and without postpartum depression were analysed according to sociodemographic characteristics (age, PHCC location, education and parity), GHQ scores, LERS events, daily medication use and acute and chronic diseases using chi-squared and t-tests. Backward multivariable logistic regression analysis was used to determine which variables were significant predictors of current depression. The dependent variable was current depression and data are presented as odds ratios and $95 \%$ confidence intervals (CI). Maternal depression was also categorized into four groups:

- No depression (women without depression over 12 weeks postpartum and at the time of the current study four years later);

- Postpartum depression only (women with depression over 12 weeks postpartum but who were not depressed four years later at the time of the current study);

- Current depression only (women without depression over 12 weeks postpartum but who were depressed four years later at the time of the current study); and

- Both postpartum depression and current depression (women who were depressed both over 12 weeks postpartum and four years later at the time of the current study)

A P-value less than 0.05 was considered statistically significant. 
Figure 1 Flow chart of sampling procedure of the study during 32-42 weeks pregnancy to four years after birth (EPDS = Edinburgh postnatal depression scale)

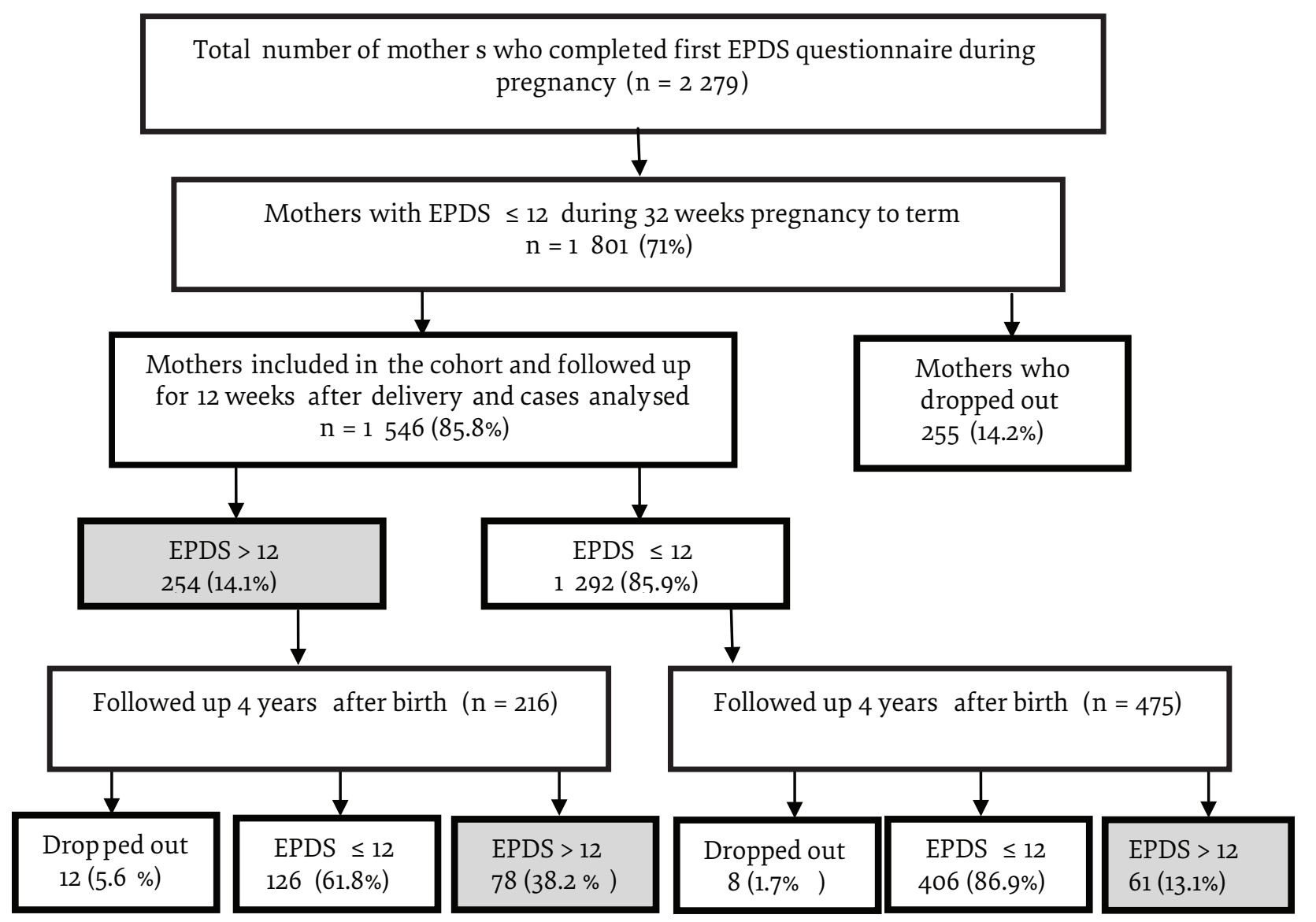

\section{Ethical considerations}

Ethical approval for the study was obtained from the Medical Ethics Committee of Mazandaran Medical Sciences University. Written consent was received from all participants and they were assured that the information in the questionnaires would be kept confidential.

\section{Results}

A total of 691 women agreed to take part in this study. Of these, 12 women with a history of postpartum depression dropped out $(5.6 \%)$, and $8(1.7 \%)$ women without depression were also excluded from the analysis because they did not complete the questionnaires. Thus, 671 (98.8\%) women completed the four-year follow-up: 204 with postpartum depression (case group) and 467 without postpartum depression (control group). There were no sociodemographic differences between the 2 groups of the participants in terms of age, PHCC location, education, parity and baby's sex (Table 1).

The mean ages of all the women and their infants in this study were 30.13 (SD 5.21) years and 47.79 (SD 1.28) months respectively. The mean EPDS and median GHQ-28 scores were 8.89 (SD 4.59) and 21.00 (SD 9.74) respectively and the mean life events number was 3.76 (SD 2.93).

Of the 671 women in the study, $78(11.6 \%)$ suffered from both postpartum depression and current depression and $406(60.5 \%)$ had not experienced any depression (Table 2).

\section{Table 1 Background of the participants}

\begin{tabular}{lccc|}
\hline Variable & $\begin{array}{c}\text { With postpartum } \\
\text { depression (n= 204) }\end{array}$ & $\begin{array}{c}\text { Without postpartum } \\
\text { depression (n= 467) }\end{array}$ & $\begin{array}{l}\text { P-value } \\
\text { Age (years) [mean (SD)] }\end{array}$ \\
Education (upper secondary, grades 10-12) [no. (\%)] & $30.10(5.13)$ & $30.14(5.25)$ & 0.43 \\
Primipara [no. (\%)] & $114(55.9 \%)$ & $226(48.4 \%)$ & 0.14 \\
Infant's age (months) [mean (SD)] & $121(59.3 \%)$ & $297(63.6 \%)$ & 0.55 \\
Child sex (female) [No. (\%)] & $47.87(0.73)$ & $47.89(0.79)$ & 0.06 \\
\hline
\end{tabular}




\begin{tabular}{lcc}
\hline Table 2 Proportion of women with depression $(\mathbf{n}=\mathbf{6 7 1})$ \\
\hline Depression & No. & $\%$ \\
\hline Both postpartum and current & 78 & 11.6 \\
Postpartum only & 126 & 18.8 \\
Current only & 61 & 9.1 \\
None & 406 & 60.5 \\
\hline
\end{tabular}

Four years after delivery, current depression was 3 times more prevalent in the women who had experienced postpartum depression than the women who had not had postpartum depression (38.2\% versus $13.1 \%, P<0.001)$. According to GHQ-28 scores, psychological distress was significantly more common in women who had had postpartum depression than the women who had not (61.8\% versus $26.6 \%, P<0.001)$. There were also significant differences between the two groups in experiencing physical illnesses (chronic diseases: 19.6\% versus 5.4\%; acute diseases: $37.3 \%$ versus $15.2 \%, P<0.001$ for both) and other mental health problems $(15.7 \%$ versus $2.8 \%, P<$ $0.001)$ as well as daily medication use (21.6\% versus $6.0 \%$, $P<0.001$ ) (Table 3).
In the multivariable logistic regression analysis, the factors significantly associated with current depression were; higher scores in the GHQ-28, having acute and chronic diseases, and experiencing postpartum depression (Cox Snell $R^{2}=0.138$ ) (Table 4). Women who had experienced postpartum depression had twice the risk of depression 4 years later (odds ratio $=2.16 ; 95 \% \mathrm{CI}$ : 1.38-3.36).

\section{Discussion}

We evaluated subsequent depression four years after childbirth in the women from northern Islamic Republic of Iran. To our knowledge, this is the first study from the developing world exploring depression recurrence and long-term consequences of postpartum depression. The majority of the women were of poor and middle socioeconomic status. The main finding was that women who had experienced postpartum depression were twotimes more likely to suffer from depression four years after childbirth than women who had not experienced postpartum depression. In similar studies from developed countries, women experiencing postpartum depression were predicted to be at a higher risk of subsequent de-

\begin{tabular}{|c|c|c|c|}
\hline \multirow[t]{2}{*}{ Variable } & $\begin{array}{l}\text { With postpartum } \\
\text { depression }(n=204)\end{array}$ & $\begin{array}{l}\text { Without -postpartum } \\
\text { depression }(n=467)\end{array}$ & P-value $^{a}$ \\
\hline & No. (\%) & No. (\%) & \\
\hline Current depression based on EPDS & & & $<0.001$ \\
\hline Yes $(>12)$ & $78(38.2)$ & $61(13.1)$ & \\
\hline No $(\leq 12)$ & $126(61.8)$ & $406(86.9)$ & \\
\hline GHQ-28 scores & & & $<0.001$ \\
\hline Unhealthy (> 21) & $126(61.8)$ & $124(26.6)$ & \\
\hline Healthy $(\leq 21)$ & $78(38.2)$ & $343(73.4)$ & \\
\hline Chronic diseases & & & $<0.001$ \\
\hline Yes & $40(19.6)$ & $25(5.4)$ & \\
\hline No & $164(80.4)$ & $442(94.6)$ & \\
\hline Acute diseases & & & $<0.001$ \\
\hline Yes & $76(37.3)$ & $71(15.2)$ & \\
\hline No & $128(62.7)$ & $396(84.1)$ & \\
\hline Other mental health problems & & & $<0.001$ \\
\hline Yes & $32(15.7)$ & $13(2.8)$ & \\
\hline No & $172(84.3)$ & $454(97.2)$ & \\
\hline Daily medication use & & & $<0.001$ \\
\hline Yes & $44(21.6)$ & $28(6.0)$ & \\
\hline No & $160(78.4)$ & $439(94.0)$ & \\
\hline Life events from LERS & & & 0.825 \\
\hline$\geq 4$ & $95(46.6)$ & $207(44.3)$ & \\
\hline $2-3$ & $64(31.4)$ & $148(31.7)$ & \\
\hline$\leq 1$ & $45(22.1)$ & $112(24)$ & \\
\hline
\end{tabular}

${ }^{a}$ Chi-squared test.

$E P D S=$ Edinburgh postnatal depression scale; $G H Q=$ general health questionnaire; $L E R S=$ life event rating scale. 
pression $(10,15)$. Other longitudinal studies also reported that postpartum depression could affect women's mental health in the long term $(9,14)$; however, earlier longitudinal studies had not found a higher prevalence of subsequent depression in women with a history of postpartum depression $(26,27)$. Socioeconomic differences between the samples could explain the different results of these studies. Moreover, different methods and tools were used in these studies, follow-up duration varied and they had fairly small sample sizes which may have been resulted in the different findings. For example, in the study by Luoma et al., 147 women were included and maternal depression was assessed immediately after birth and when the children were 8-9 years old (27). Cooper and Murray assessed recurrent depression using a structured clinical interview in 40 women 5 years after giving birth (26).

There was a significant difference between the women with a history of postpartum depression and those without in terms of physical illness, daily medication use and psychiatric distress related to general medical illness (measured by GHQ-28). In a study in Sweden, history of postpartum depression was shown to be a risk factor for negative health outcomes in the sample of women (10). The authors reported that women with a history of postpartum depression were more vulnerable to illnesses and likely to be on treatment with daily medication than those with no history of postpartum depression (10). A consequence of postpartum depression is reduced quality of life and increased likelihood of risky behaviour that may eventually lead to high morbidity in women $(11,28,29)$. In our study, $19.6 \%$ of the women with postpartum depression suffered from chronic diseases, which required further interventions.

Although psychosocial stressors may have affect the development of postpartum depression (30), there was no significant difference between the 2 groups in our study in terms of life events. A recent review concluded that the majority of these psychosocial factors are largely social in nature (3).

A limitation of our study was using the EPDS - and not a structured clinical interview - to detect depression. EPDS was developed to identify depression in the postpartum period, although there are many similarities between this scale and other depression scales, and some studies have concluded that the EPDS is suitable for screening major depressive episode among men, in antepartum and postpartum women, and in the community (31-33). Indeed, items from EPDS are derived from other depression scales. Moreover, we used a selfreported questionnaire with retrospective data which may lead to recall bias. Another limitation of our study was failing to contact all depressed women in the case group, especially in urban areas, which led to selection bias. We also did not have any data on the women who dropped out. Moreover, other demographic characteristics and depression predictors were not evaluated, which may have acted as confounders.

\section{Conclusion}

Our results suggest that postpartum depression predisposed women to subsequent depression and other physical and mental illnesses later on. Our study was carried out in one area of the Islamic Republic of Iran and therefore generalization of the results should be considered with caution. Replication of our study in other Iranian societies is recommended. Our results indicate the need to identify and follow up women with postpartum depression early after delivery or during their perinatal health clinic visits. Early identification of women who are at risk of subsequent depression and giving them more support and appropriate psychosocial and medical interventions can improve their mental and physical health.

\section{Acknowledgements}

We would like to thank the women who participated in this study and also the health workers in PHCCs for their assistance in data collection.

Funding: This study was supported by a grant from the Mazandaran University of Medical Sciences (No: 139265).

Competing interests: None declared.

\section{Effet de la dépression postpartum sur la santé mentale et physique des femmes quatre ans après la naissance}

\section{Résumé}

Contexte : Il a été démontré que la dépression postpartum a un impact sur la santé des femmes à long terme, mais aucune étude n'avait encore cherché à évaluer cet impact en République islamique d'Iran.

Objectifs : La présente étude a déterminé la prévalence de la maladie et de la dépression courante quatre ans après la naissance chez les femmes ayant souffert d'une dépression postpartum et évalué les facteurs associés à la dépression courante.

Méthodes : Dans une étude de cohorte réalisée en 2009, 1801 femmes enceintes sans dépression à 32-42 semaines de grossesse qui consultaient dans les centres de soins de santé primaires de Mazandaran ont été examinées à la recherche de dépression postpartum à l'aide de l'échelle de dépression postnatale d'Édimbourg (Edinburgh Postnatal Depression Scale, EPDS). Quatre ans plus tard, 204 femmes de la cohorte initiale ayant souffert de dépression postpartum et 467 femmes 
de la cohorte sans dépression postpartum ont été évaluées de nouveau à l'aide de l'EPDS et d'autres questionnaires pour déterminer la prévalence de la dépression courante et d'autres problèmes de santé. Une analyse de régression logistique multivariable a été utilisée pour évaluer les facteurs associés à la dépression courante et aux autres problèmes de santé.

Résultats : L'âge moyen des femmes était de 30,13 ans (ET 5,21). Les femmes ayant vécu une dépression postpartum étaient deux fois plus susceptibles de souffrir de dépression quatre ans après avoir donné naissance $(\mathrm{OR}=2,16$ et IC à $95 \%: 1,38-3,36)$. Elles étaient aussi beaucoup plus susceptibles de souffrir de maladies chroniques (OR $=2,49$ et IC à $95 \%$ : $1,38-4,50)$ et d'obtenir un score plus élevé au Questionnaire général de santé (OR = 2,50 et IC $95 \%: 1,38-4,50$ ).

Conclusions : La dépression postpartum prédispose les femmes à une dépression ultérieure et à d'autres problèmes de santé mentale et physique. Les femmes souffrant de dépression postpartum doivent être identifiées et bénéficier de soutien et d'interventions appropriées afin d'éviter les problèmes de santé ultérieurs.

$$
\text { تأثير الاكتئاب التالي للو لادة على الصحة النفسية والجسدية للمر أة بعد أربع سنوات على الو لادة }
$$

الخلفية: أصبح من الثابت أن الاكتئاب يؤثر على صحة المرأة على المدى الطويل، ولكن لا توجد دراسات لتقييم هذا التأثير في جمهورية إيران

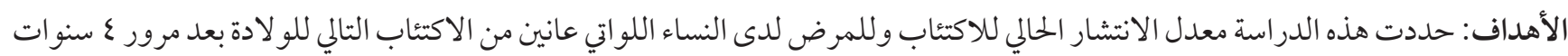
على الولادة، مع تقييم العوامل المرتبطة بالاكتئاب الخالي.

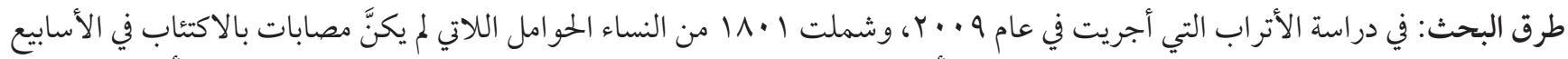

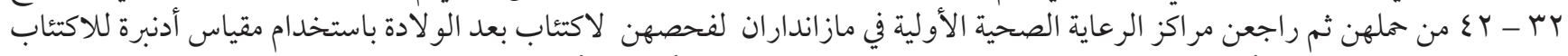

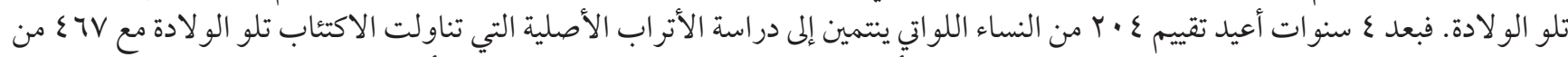

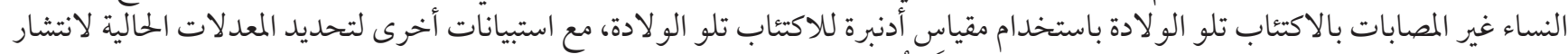

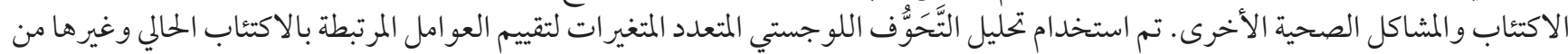
المشاكل الصحية.

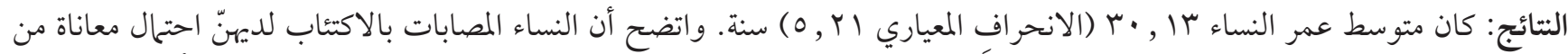

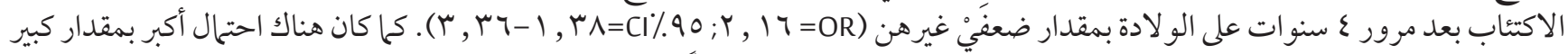

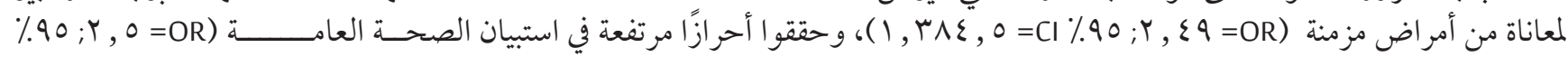
. $(\varepsilon, 0-1, \mathrm{r} \wedge=\mathrm{Cl}$

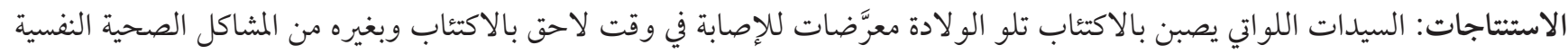

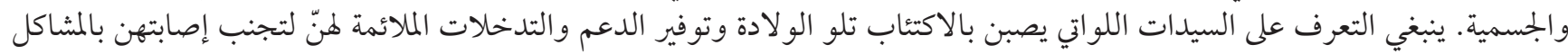
الصحية في وقت لاحقة.

\section{References}

1. Ferrari A, Somerville A, Baxter A, Norman R, Patten S, Vos T, et al. Global variation in the prevalence and incidence of major depressive disorder: a systematic review of the epidemiological literature. Psychol Med. 2013 Mar;43(3):471-81. https://doi. org/10.1017/So033291712001511 PMID:28069271

2. Sadeghirad B, Haghdoost AA, Amin-Esmaeili M, Ananloo ES, Ghaeli P, Rahimi-Movaghar A, et al. Epidemiology of major depressive disorder in Iran: a systematic review and meta-analysis. Int J Prev Med. 2010 Spring;1(2):81-91. PMID:21566767

3. Norhayati MN, Nik Hazlina NH, Asrenee AR, Wan Emilin WMA. Magnitude and risk factors for postpartum symptoms: a literature review. J Affect Disord. 2015 Apr 1;175:34-52. https://doi.org/10.1016/j.jad.2014.12.041 PMID:25590764

4. Fisher J, Mello MCd, Patel V, Rahman A, Tran T, Holton S, et al. Prevalence and determinants of common perinatal mental disorders in women in low-and lower-middle-income countries: a systematic review. Bull World Health Organ. 2012 Feb 1;90(2):13949. https://doi.org/10.2471/BLT.11.091850 PMID:22423165

5. Lilja G, Edhborg M, Nissen E. Depressive mood in women at childbirth predicts their mood and relationship with infant and partner during the first year postpartum. Scand J Caring Sci. 2012 Jun;26(2):245-53. https://doi.org/10.1111/j.1471-6712.2011.00925.x PMID:21950600

6. Veisani Y, Delpisheh A, Sayehmiri K, Rezaeian S. Trends of postpartum depression in Iran: a systematic review and meta-analysis. Depress Res Treat. 2013;2013. http://dx.doi.org/10.1155/2013/291029

7. Whitaker RC, Orzol SM, Kahn RS. Maternal mental health, substance use, and domestic violence in the year after delivery and 
subsequent behavior problems in children at age 3 years. Arch Gen Psychiatry. 2006 May;63(5):551-60. https://doi.org/10.1001/ archpsyc.63.5.551 PMID:16651512

8. Surkan PJ, Kennedy CE, Hurley KM, Black MM. Maternal depression and early childhood growth in developing countries: systematic review and meta-analysis. Bull World Health Organ. 2011 Aug 1;89(8):608-15. https://doi.org/10.2471/BLT.11.088187 PMID:21836759

9. Mallikarjun PK, Oyebode F. Prevention of postnatal depression. J R Soc Promot Health. 2005 Sep;125(5):221-6. https://doi. org/10.1177/146642400512500514 PMID:16220736

10. Josefsson A, Sydsjö G. A follow-up study of postpartum depressed women: recurrent maternal depressive symptoms and child behavior after four years. Arch Women Ment Health. 2007;10(4):141-5. https://doi.org/10.1007/s00737-007-0185-9 PMID:17533557

11. Chaudron LH. Postpartum depression: what pediatricians need to know. Pediatr Rev. 2003 May;24(5):154-61. https://doi. org/10.1542/pir.24-5-154 PMID:12728188

12. Oates M. Perinatal psychiatric disorders: a leading cause of maternal morbidity and mortality. Br Med Bull. 2003;67(1):219-29. https://doi.org/10.1093/bmb/ldg011 PMID:14711766

13. Wisner KL, Sit DK, McShea MC, Rizzo DM, Zoretich RA, Hughes CL, et al. Onset timing, thoughts of self-harm, and diagnoses in postpartum women with screen-positive depression findings. JAMA Psychiatry. 2013 May;70(5):490-8. https://doi.org/10.1001/ jamapsychiatry.2013.87 PMID:23487258

14. Vliegen N, Casalin S, Luyten P. The course of postpartum depression: a review of longitudinal studies. Harv Rev Psychiatry. 2014 Jan-Feb;22(1):1-22. https://doi.org/10.1097/HRP.0000000000000013 PMID:24394219

15. Agnafors S, Sydsjö G, Dekeyser L, Svedin CG. Symptoms of depression postpartum and 12 years later-associations to child mental health at 12 years of age. Matern Child Health J. 2013 Apr;17(3):405-14. https://doi.org/10.1007/s10995-012-0985-z PMID:22466717

16. Vliegen N, Luyten P, Besser A, Casalin S, Kempke S, Tang E. Stability and change in levels of depression and personality: a follow-up study of postpartum depressed mothers that were hospitalized in a mother-infant unit. J Nerv Ment Dis. 2010 Jan;198(1):45-51. https://doi.org/10.1097/NMD.obo13e3181c8aa57 PMID:20061869

17. Campbell SB, Brownell CA, Hungerford A, Spieker SJ, Mohan R, Blessing JS. The course of maternal depressive symptoms and maternal sensitivity as predictors of attachment security at 36 months. Dev Psychopathol. 2004 Spring;16(2):231-52. PMID:15487594

18. Cornish AM, McMahon C, Ungerer JA. Postnatal depression and the quality of mother-infant interactions during the second year of life. Aust J Psychol. 2008;60(3):142-51. https://doi.org/10.1080/00049530701477738.

19. Abdollahi F, Zarghami M, Azhar MZ, Sazlina SG, Lye MS. Predictors and incidence of post-partum depression: a longitudinal cohort study. J Obstet Gynaecol Res. 2014 Dec;40(12):2191-200. https://doi.org/10.1111/jog.12471 PMID:25132641

20. Cox JL, Holden JM, Sagovsky R. Detection of postnatal depression. Development of the 10-item Edinburgh Postnatal Depression Scale. Br J Psychiatry. 1987 Jun;150(6):782-6. https://doi.org/10.1192/bjp.150.6.782 PMID:3651732

21. Holmes TH, Rahe RH. The Social Readjustment Rating Scale. J Psychosom Res. 1967 Aug;11(2):213-8. https://doi.org/10.1016/o0223999(67)90010-4 PMID:6059863

22. Goldberg D. The detection of psychiatric illness by questionnaire. Oxford: Oxford University Press; 1972.

23. Yaghobi N, Nasresfehanian M, Shahmohamadi D. [Study of mental health in Somesara. Gilan]. Journal of Thinking and Behavior. 1995;1(4):55-65 [In Farsi].

24. Kheirabadi GR, Maracy MR, Akbaripour S, Masaeli N. Psychometric properties and diagnostic accuracy of the edinburgh postnatal depression scale in a sample of Iranian women. Iran J Med Sci. 2012 Mar;37(1):32-8. PMID:23115428.

25. Noorbala A, Mohammad K. [The validation of general health questionnaire-28 as a psychiatric screening tool]. Hakim Health Sys Res 2009;11(4):47-53 [In Farsi].

26. Cooper PJ, Murray L. Course and recurrence of postnatal depression. Evidence for the specificity of the diagnostic concept. Br J Psychiatry. 1995 Feb;166(2):191-5. https://doi.org/10.1192/bjp.166.2.191 PMID:7728362

27. Luoma I, Tamminen T, Kaukonen P, Laippala P, Puura K, Salmelin R, et al. Longitudinal study of maternal depressive symptoms and child well-being. J Am Acad Child Adolesc Psychiatry. 2001 Dec;40(12):1367-74. PMID:11765281.

28. Da Costa D, Dritsa M, Rippen N, Lowensteyn I, Khalifé S. Health-related quality of life in postpartum depressed women. Arch Women Ment Health. 2006 Mar;9(2):95-102. https://doi.org/10.1007/s00737-005-0108-6 PMID:16231095

29. Sadat Z, Abedzadeh-Kalahroudi M, Atrian MK, Karimian Z, Sooki Z. The impact of postpartum depression on quality of life in women after child's birth. Iran Red Crescent Med J. 2014 Feb;16(2):el4995. https://doi.org/10.5812/ircmj.14995 PMID:24719747

30. Norhayati M, Hazlina NN, Asrenee A, Emilin WW. Magnitude and risk factors for postpartum symptoms: A literature review. J J Affect Disord. 2015 Apr 1;175:34-52. https://doi.org/10.1016/j.jad.2014.12.041 PMID:25590764

31. Matijasevich A, Munhoz TN, Tavares BF, Barbosa APPN, da Silva DM, Abitante MS, et al. Validation of the Edinburgh Postnatal Depression Scale (EPDS) for screening of major depressive episode among adults from the general population. BMC Psychiatry. 201410 8;14(1):284. https://doi.org/10.1186/s12888-014-0284-x PMID:25293375 
32. Gibson J, McKenzie-McHarg K, Shakespeare J, Price J, Gray R. A systematic review of studies validating the Edinburgh Postnatal Depression Scale in antepartum and postpartum women. Acta Psychiatr Scand. 2009 May;119(5):350-64. https://doi.org/10.1111/ j.1600-0447.2009.01363.x PMID:19298573

33. Edmondson OJ, Psychogiou L, Vlachos H, Netsi E, Ramchandani PG. Depression in fathers in the postnatal period: assessment of the Edinburgh Postnatal Depression Scale as a screening measure. J Affect Disord. 2010 Sep;125(1-3):365-8. https://doi. org/10.1016/j.jad.2010.01.069 PMID:20163873 